University at Albany, State University of New York

Scholars Archive

Communication Faculty Scholarship

Communication

$12-1998$

\title{
Offering a candidate answer: An information seeking strategy
}

Anita Pomerantz

University at Albany, State University of New York, apomerantz@albany.edu

Follow this and additional works at: https://scholarsarchive.library.albany.edu/

cas_communication_scholar

Part of the Arts and Humanities Commons

\section{Recommended Citation}

Hayano, K. 2013. Question Design in Conversation. In J. Sidnell and T. Stivers (eds) The Handbook of Conversation Analysis. Malden, MA: Wiley-Blackwell, pp395-414. Pomerantz, A. (2012). Candidate answer queries, actions, and the moral order. In R. Ayass \& C. Meyer (Eds.), Sociality in Slow Motion: Festschrift for Jorg Bergmann (pp. 333-352). Frankfurt: Velbrueck.

This Article is brought to you for free and open access by the Communication at Scholars Archive. It has been accepted for inclusion in Communication Faculty Scholarship by an authorized administrator of Scholars Archive. For more information, please contact scholarsarchive@albany.edu. 
This article was downloaded by: [National Communication Association]

On: 14 May 2014, At: 14:48

Publisher: Routledge

Informa Ltd Registered in England and Wales Registered Number: 1072954

Registered office: Mortimer House, 37-41 Mortimer Street, London W1T 3JH, UK

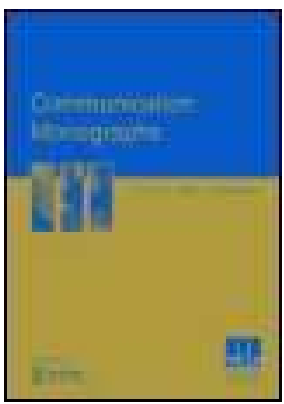

\title{
Communication Monographs
}

Publication details, including instructions for authors and subscription information:

http:/ / nca.tandfonline.com/loi/ rcmm20

\section{Offering a candidate answer: An information seeking strategy}

\author{
Anita Pomerant $z^{a}$ \\ ${ }^{a}$ Assistant Professor of Rhetoric and Communication, Temple \\ University, \\ Published online: 02 Jun 2009.
}

To cite this article: Anita Pomerantz (1988) Offering a candidate answer: An

information seeking strategy, Communication Monographs, 55:4, 360-373, DOI:

$10.1080 / 03637758809376177$

To link to this article: http:/ / dx.doi.org/ 10.1080/ 03637758809376177

\section{PLEASE SCROLL DOWN FOR ARTICLE}

Taylor \& Francis makes every effort to ensure the accuracy of all the information (the "Content") contained in the publications on our platform. However, Taylor \& Francis, our agents, and our licensors make no representations or warranties whatsoever as to the accuracy, completeness, or suitability for any purpose of the Content. Any opinions and views expressed in this publication are the opinions and views of the authors, and are not the views of or endorsed by Taylor \& Francis. The accuracy of the Content should not be relied upon and should be independently verified with primary sources of information. Taylor and Francis shall not be liable for any losses, actions, claims, proceedings, demands, costs, expenses, damages, and other liabilities whatsoever or howsoever caused arising directly or indirectly in connection with, in relation to or arising out of the use of the Content.

This article may be used for research, teaching, and private study purposes. Any substantial or systematic reproduction, redistribution, reselling, loan, sub-licensing, systematic supply, or distribution in any form to anyone is expressly forbidden.

Terms \& Conditions of access and use can be found at http://nca.tandfonline.com/ page/terms-and-conditions 


\title{
OFFERING A CANDIDATE ANSWER: AN INFORMATION SEEKING STRATEGY
}

\author{
ANITA POMERANTZ*
}

Interactants use a variety of strategies to seek information from one another. One strategy involves incorporating a Candidate Answer in a query. In using this strategy, a speaker provides a model of the type of answer that would satisfy his/her purpose-for-asking. Supplying a model is useful when a speaker wants to guide, direct, or assist a respondent in providing particular information. In offering a Candidate Answer, a speaker can display having knowledge and familiarity of a circumstance. A Candidate Answer can be read as revealing the speaker's attitude toward, and expectations of, relevant others.

7 HERE ARE a host of circumstances in which members of our culture seek 1 information. We seek information when we get to know others and when we coordinate our activities with others. We often seek information when we encounter unexpected problems and when we experience uncertainty. We seek information at home, at work, and in public. Information seeking is a commonplace activity.

Competent members of the culture use a variety of techniques for seeking information from one another. Interactants select their techniques according to what they judge to be appropriate, effective, right, expedient, etc. in each situation. The various techniques differ from one another with respect to their occasions of use, functions, and consequences.

One of the ways that we elicit information is by incorporating a candidate answer in a query. The following are examples of this technique.

"And have you been treated all right by the police?

"Is that in any way related to the police, that bruise?"

"Was Tom home from school ill today?"

"Did you just see me pull up?"

"Did you step out for a few minutes?"

"Are you going to be here for awhile?"

"Is that Temple?"

"Should I just go ahead and pick that up and put in a couple of tiles to build it up?"

"Do you have a sign-in today?"

This paper explores the shared knowledge and reasoning that participants rely on in using and understanding this method of seeking information. The sections that follow include the methods, the data, the analysis, and the concluding discussion of the relationship of this research to other research in the field.

\section{ETHNOMETHODOLOGY AND CONVERSATION ANALYSIS}

This study was carried out using an ethnomethodological/conversation analytic perspective. As described by Pomerantz and Atkinson (1984), there are at least three central points on which most ethnomethodologists and conversation analysts agree. The first is that the main focus should be on how participants themselves produce

*Anita Pomerantz is Assistant Professor of Rhetoric and Communication at Temple University. The author would like to thank Karen Tracy, Robert T. Craig, Joseph Folger, and an anonymous reviewer for their helpful comments. 
and interpret each other's actions. The second is that an analyst must be willing to treat ordinary events as worthy of serious analytic attention. The third is that there is a strong preference for working with naturally occurring interactions rather than experimental or survey data.

Ethnomethodologists and conversation analysis seek to discover the interpretive practices through which interactants produce, recognize, and interpret their own and others' actions.

At its most basic, this objective is one of describing the procedures by which conversationalists produce their own behavior and understand and deal with the behavior of others. A basic assumption throughout is Garfinkel's (1967:1) proposal that these activities-producing conduct and understanding and dealing with it-are accomplished as the accountable products of common sets of procedures. (Heritage \& Atkinson, 1984, p. 1)

\pm The research stance taken is that participants' actions, roles, and relationships may be seen as productions or accomplishments to be studied (Garfinkel, 1967).

Guided by this perspective, conversation analysts start by observing the details of interaction(s). Usually after considerable observation, an analyst may come up with a proposal concerning an aspect of social organization. An analytic proposal may attempt to account for how the details of the interaction came to be produced in the way that they appear in the datum. After a proposal is formulated, the analyst continues to examine any and all possibly relevant cases to determine if the proposal is substantiated or if it needs to be modified.

The methods of conversation analysts/ethnomethodologists have at least two points in common with a method called analytic induction. One common point is that with both methods, researchers are committed to treat their theories, proposals, or explanations as provisional and are prepared to make whatever revisions are appropriate as disconfirming cases are encountered. A second common point is that the method that is used to do research provides for both discovering proposed features of social organization and testing the validity of the proposals. Jackson's description (1986) of analytic induction as a method of both discovery and testing applies as well to conversation analysis/ethnomethodology.

An initial test of the hypothesis is its adequacy as an account of the examples. But this is only a preliminary step. The method of analytic induction is driven by a falsificationist attitude, which subjects any hypothesis about discourse structure to critical examination. The method of analytic induction requires that empirical claims be tested through active, procedurally diverse search for counterexamples. (p. 129)

In discussing how analytic research can be evaluated, Katz (1983) argues that the type of text produced by analytic researchers facilitates subsequent tests of the findings by its readers.

Analytic field research also more democratically empowers readers to become subsequent testers.... Qualitative research reports properly may be regarded as good to the extent that readers test them in application to new data in the very process of reading. Underlying the reader's experience in "recognizing" as valid or rejecting as "artificial" an analytic formulation in a qualitative text is an implicit application to phenomena within the reader's experience, to new data existing beyond the reach of the original research. (p. 145)

Offering a Candidate Answer is an extremely common method of information seeking. In our natural environments, numerous instances occur daily around us. The massive use of this strategy provides for the readers of the text ample opportunity to check out the validity of the analysis. 
DATA

I originally developed the analysis on a series of six telephone calls in which a clerk in a high school attendance office telephoned the homes of absent students. The clerk was investigating the reasons for the students' absences. The telephone calls were recorded and transcribed following the conventions developed by Jefferson (1985; Sacks, Schegloff, \& Jefferson, 1974).

Based on close and repeated examination of the tapes and transcripts, I formulated some initial analytic proposals regarding the two methods that the clerk used to gather information regarding the students' absences. As I had previously written on one of the methods, i.e. giving information to seek information, I concentrated on the other method, i.e. offering a Candidate Answer.

Since formulating the initial analytic proposals, I have continued to collect instances in which interactants offer Candidate Answers. There is no shortage of data: This method of seeking information is used pervasively in our culture. I reviewed my collections of tapes of natural interaction, I asked students to record instances in their homes, and I made field notes of ones that I encountered or overheard. With the added data, I have substantiated and refined the analysis.

\section{ANALYSIS}

The analysis is divided into two sections. The first section lays out some general features of information seeking; the second section analyzes the information-seeking strategy of offering a Candidate Answer. The analysis also shows how the general features of information seeking operate when an interactant seeks information by offering a Candidate Answer.

\section{General Features of Information Seeking}

Two features of seeking information are (A) that the information-seeker's purpose (as known or inferred) is relevant for a recipient's determination of what information to give and in what way to give it, and (B) that the speaker's knowledge and the recipient's knowledge of the matter at hand are necessarily relevant in informationseeking.

\section{Responding to the Purpose of Information Seeking}

In our culture, information seeking is sensical when performed by someone with a purpose for seeking the information. The lay model used for engaging in information seeking and the interpretive schema used for understanding and responding to information seeking is that seeking information is a motivated and purposeful action, performed in response to a warranting circumstance.

The lay model for someone to be an information-seeker is that he/she is in, or encounters, a circumstance that warrants seeking information. The circumstance, such that it is, provides a reason for his/her seeking the information. An informationseeker in our culture accountably has a purpose for seeking the particular information and is expected to know the purpose.

When co-interacting with (or observing) an information-seeker, the co-interactant uses this model or schema. The co-interactant presumes that the information-seeker has a purpose for seeking the information. While a purpose may be explicitly 
formulated for a co-interactant, many times it is not. When it is not, a co-interactant may infer a purpose through everyday reasoning practices.

One use that co-interactants make of the purposes they infer is to understand events. The following two examples illustrate how interactants understand information seeking events in terms of the information-seeker's purpose for asking. Illustration 1 is a case in which the information-seeker's purpose was not formulated and apparently was unproblematic; Illustration 2 is a case in which the informationseeker's purpose apparently was problematic and was solicited.

\section{Illustration 1}

\section{[Fieldnotes]}

I parked my car and was walking to my office at Temple University. A block away from the building, a $\searrow$ truck pulled over and the passenger pointed up the street and asked, "Is that Temple?" I confirmed that $\underset{\mathrm{C}}{\mathrm{i}}$ it was.

The man asking for the information did not offer a reason for seeking the information. Yet $I$ saw the request in terms of his attempt to get to Temple University. His publicly available circumstance was that he was in a car going $\underset{+}{*}$ somewhere. As a member of this culture, I knew that drivers typically have destinations and that drivers sometimes go to unfamiliar destinations. I assumed that his seeking information about the location of Temple University was responsive to his concern (as I inferred it) to arrive there.

\section{Illustration 2}

\section{[Fieldnotes]}

I am driving to my office at about 8:30 Sunday morning. I turn onto a one way street and half way down the road a van is stopped, blocking my way. When I pull behind the van, I can see a driver in it and notice the word "Paratransit" written on the back of the van. I wait a short while and then quickly beep the horn. I doubt that the driver heard my horn. I'm getting impatient but wonder if the driver might be E waiting to take an incapacitated person to church. I debate about whether to back up and take another street. Then I realize I could ask the driver for information.

I get out of my car and approach his van on the driver's side. He sees me, obviously waiting to speak to him, and rolls down his window.

1 ask, "Are you gonna be here awhile?"

He shakes his head no and has a puzzled look on his face.

I say, " 'Gause I'm behind you."

He says, "I'm sorry, I didn't see you."

I return to my car as he starts his van and pulls down the block to a parking space.

My purpose in seeking information was to find out how long the van would be in the middle of the road so I could decide whether to back up or wait. In response to my question, "Are you gonna be here long?" the van driver indicated that he would not be there for long and that he was puzzled. I saw his puzzlement in terms of his not understanding why I was asking. When I described my car's position relative to his van's, the puzzlement disappeared.

In both of these illustrations, the parties sought information without stating their purposes for seeking it. In the first case, I inferred a purpose for the question about Temple University and the event went off without a hitch. In the second case, the van driver apparently had difficulty determining my purpose and, through his expression, solicited an explanation.

When a co-interactant infers a purpose, he/she gains an understanding or sense of 
an event. Understanding as a cognitive state, however, is not the only use of a co-interactant's inferring a purpose. A co-interactant often uses the inferred purpose in responding to the inquiry: in selecting just what information is relevant and appropriate to say and at what level of detail.

In Illustration 2, the van driver gave me a minimal response (shook his head "no") while he solicited further information regarding my purpose for asking. When my purpose became clear to him (that is, that I wanted to travel on), he responded to the purpose and removed the obstacle.

That co-interactants use the inferred purpose in responding to an inquiry is particularly visible in Illustrations 3-5. In each case, a co-participant offers information that is more than what is literally asked for, information which addresses the inferred purpose of the information-seeker.

\section{Illustration 3}

A high school attendance office clerk phoned the home of an absent student to check on the absence. In response to the clerk's question, "Was Arthur home from school ill toda:y?", the mother checked with a man in the house and reported back to the clerk, "No he wasn't."

Although the mother had supplied information regarding whether or not her son was home ill that day, a few seconds later in the call she supplied additional information to the clerk.

[Med.5]

Mother: Oh waita minute. Ah- (.) Waita minute.

Clerk: Oka:y,

Mother: Ah he hadda do:ctor's appointment. [That's right.

Clerk:

[Ah:huh.

What the mother remembered and reported was that her son had a legitimate reason to be absent. The mother would have inferred, given the clerk's question, "Was Arthur home from school ill today?" that the clerk was calling to find out whether Arthur's absence was legitimate or not. The information that the mother reported, then, was responsive to the inferred purpose.

\section{Illustration 4}

[Fieldnotes]

Sally: Did you step out for a few minutes?

Ann: No. I took a shower.

Sally: Linda called me. She's gonna take the day off. . .

In response to Sally's question, "Did you step out for a few minutes?", Ann indicated that she did not and added the information, "I took a shower." In that Sally offered a possible explanation for Ann's not answering the phone, Ann may have inferred that Sally wanted an explanation for it. The information that Ann supplied, "I took a shower," satisfied Sally's query, as inferred.

\section{Illustration 5}

[TC]

(Sue phones her friend and neighbor, Gail. This fragment occurs close to the beginning of the call.)

Sue: So how are you.

Gail: Okay::dju j'see me pull up?

Sue: No:: I wz trying you all day.en the line wz busy fer like hours 
Gail sought information with her question, “Dju j'see me pull up?". Sue indicated that she did not and added, "I wz trying you all day.en the line wz busy fer like hours." In that Gail offered a possible explanation for the timing of Sue's call so soon after Gail arrived home, Sue may have inferred that Gail wanted to know how the call was timed. With the information that she supplied, Sue implied a different explanation for the timing, that this call was one in a series of many attempts.

To reiterate, I have argued in this section that recipients of requests for information use their knowledge and/or inferences of the information seekers' purposes-for-asking in determining just what information to supply (what kind of information, how much, what level of detail, etc.) Parenthetically, the fact that recipients of requests for information may be counted on to infer the purposefor-asking provides for the useability of information seeking for indirect speech acts, I for example, indirect requests. When I asked the owner of a takeout pizza shop, "Do ¿े you have a white phone book?" he (correctly) inferred that my purpose for asking for the information was that I wanted to use it.

\section{The Relevance of Speaker's Knowledge and Recipient's Knowledge}

In information seeking, speakers make implicit claims about their own state of knowledge and imply expectations regarding the recipients' knowledge.

In seeking information, speakers implicitly propose that they do not have, or are not certain about, the sought-after information. That the speaker's state of mind is unknowing or uncertain provides legitimacy to the information-seeking act. Although this is constitutive of the organization of information seeking, information \& seekers have ways of displaying more or less knowledge and/or certainty. This point of is elaborated later.

In information seeking, speakers build into their questions expectations or presumptions regarding the recipients' knowledge. With an unmarked question, for Example, "What time is it?", a speaker implies that the recipient is expected to know ô the answer. With markers, for example, "Would you know..." or "Would you happen to know...", a speaker indicates that he/she does not expect or presume that the recipient knows the answer.

In the following illustration, the two information seeking attempts have different z implied presumptions or expectations for the recipient.

\section{Illustration 6}

[Fieldnotes]

Al: Is Peter here?

Bob: No.

$\mathrm{Al}$ : Do you know where he is?

In the first question, $\mathrm{Al}$ asked $\mathrm{Bob}$ whether Peter was at that location. When Bob disconfirmed, $\mathrm{Al}$ asked Bob a second question regarding Peter's whereabouts. In the first question, $\mathrm{Al}$ presumed that Bob should have known whether Peter was at that location. In the second question, however, Al did not presume that Bob should have known the answer. In asking "Do you know..." he allowed for the possibility that Bob may not have known. Al presumed that Bob should have had knowledge of the more limited domain referenced in his first query ("Is Peter here?") but did not presume that Bob should have had knowledge of the larger domain referenced in the second question ("Where is he?"). 
A speaker unavoidably builds into an information-seeking question an expectation that the recipient should know, may know, probably does not know, etc. the sought-after information. What a speaker expects a recipient to know or not know bears on whether or not the speaker seeks information from the recipient. If a speaker does seek information, the speaker's expectation regarding the recipient's knowledge bears on what information he/she asks for and in what way he/she asks for it.

Consider again Illustration 3 from the high school attendance office. The clerk wanted to find out whether Arthur's absence was an excused absence or a truancy. In phoning the mother, she formed the question to ask about whether Arthur was home ill that day. In her choice of just what information to ask for, she asked the mother to report on whether Arthur was home ill rather than to report on Arthur's whereabouts. She asked for information that she expected the mother to know and implied with the unmarked question the expectation that the mother ought to know the answer.

\section{Offering a Candidate Answer}

A typical scenario for a participant's seeking information is as follows: a participant is in a circumstance that provides a reason for seeking information. The participant has available or locates a co-participant who may or should supply the information. At this point, the participant may have a choice of strategies available to elicit the information.

One option is to incorporate a Candidate Answer in a question to the recipient. The choice of this strategy is both responsive to, and helps shape, the nature of the situation. The analysis presented in this section shows how this strategy works; it describes some interactional features and relational consequences of its use.

This section analyzes the implications of two features of Offering a Candidate Answer. One feature is that a speaker provides a model to the recipient of what type of information would satisfy the speaker's purpose. A second feature is that a speaker accountably authors the Candidate Answer.

\section{Providing the Recipient with a Model Answer.}

When recipients are asked to supply information, there are various types of considerations that bear on just what information they provide. As discussed in the previous section, one type of consideration that bears on what information recipients offer is relevancy: They attempt to determine what information is relevant to the information seekers' (stated or inferred) purposes.

An information-seeker has options as to how much or how little guidance to give a recipient with respect to what information is relevant and appropriate. When interactants incorporate Candidate Answers in their inquiries, they give the co-interactants models ${ }^{1}$ of the types of answers that would satisfy their purposes. In providing a model, an interactant instructs a co-interactant as to just what kind of information is being sought.

Sacks $(1964,1966,1966,1967)$ described offering a Candidate Answer as a "correction invitation" device. Sacks' term "correction invitation" was derived from the feature that this type of "yes-no" question invites correction and elaboration. A speaker who uses a correction invitation device implicitly asks the recipient to either confirm the guess as correct or provide the correct answer if the guess is wrong. In friendly social discourse, a recipient often will satisfy the inferred purpose of the inquiry by supplying additional information (See Illustrations 3-5). 
The feature of providing an answer as a model to a recipient is useful in a variety of circumstances. It is useful when an interactant seeks some particular information or seeks information given in a particular way. It is useful when an interactant values efficiency in getting particular information. It is useful when an interactant anticipates or observes a co-interactant having difficulty giving a satisfactory answer without a model. In short, offering a Candidate Answer is functional whenever a speaker has a reason to guide a co-participant to respond in a particular way.

Illustrations 7 and 8 point to two circumstances in which interactants' Candidate Answers serve as models.

\section{Illustration 7}

[PD]

$\checkmark$ (The following dialogue was excerpted from a videotaped session between an assistant district attorney (ADA) and a murder suspect. The suspect had agreed to videotape his version of committing the murder for use in his upcoming trial. A videotape is inadmissible as evidence if the suspect is coerced to make it. $\sum$ The ADA's instructions for producing the videotapes included establishing at the beginning of the Interview that no coercion had been used.)

ADA: And have you been treated all right by the police?

$\ddot{ \pm}$ Sus: Yes

EADA: Okay now I see that there::s a br::uise on your arm and it's pretty noticeable I want you jus if you ठี Sus: N::0

can show it to the camera did is that in any way related to the police that bruise?

ADA: How? did you get that bruise

Sus: I was in a fight last night

DDA: Where did the fight take place?

Sus: Uhm my neighborhood uhm hh I jus I forget what street it was down (0.5) eighty-eighth street (0.7) I gue::ss.

ADA: Okay. So the police had no part of that.

Sus: No

The ADA sought information with Candidate Answers in two questions: "And have ठुyou been treated all right by the police?" and "Is that in any way related to the Epolice, that bruise?" Both the ADA and the suspect wanted to produce an admissible . videotape and hence they needed to establish that the police had not maltreated the Żंsuspect.

In seeking information, an interactant anticipates whether the recipient should be able to supply the sought-after information. While the ADA would expect the gsuspect to know and be able to report on how he has been treated by the police, he Oूmay well assume that the suspect is not knowledgeable about just what it would take Fo refute a possible charge of maltreatment in court.

Had the ADA asked the suspect to report on how the police had treated him, for example, "How have the police treated you?", the suspect would have been in a position of determining what a satisfactory answer might be. At the very least, he would have needed to determine what sort of assessment to give and whether or not to detail their treatment of him. By incorporating a Candidate Answer, "treated all right," the ADA instructed the suspect on what type of answer would satisfy their purpose: a confirmation of "treated all right" or a replacement for it. In this case, the suspect confirmed it and the ADA moved on to the next item.

With the next question, "Is that in any way related to the police, that bruise?" the ADA would have assumed that the suspect knew how he got the bruise and that he could describe it. Instead of leading off with a question asking for an account of how he got the bruise (for example, the ADA's next question was "How did you get that 
bruise"), the ADA used his lead question to focus on the one account of the bruise that was relevant for the immediate purpose. (Had the bruise been a result of police brutality, the testimony on the videotape would have been inadmissible in court.) The ADA incorporated the one relevant account for the bruise in his Candidate Answer. In doing so, he provided for the suspect's confirmation or denial of the account that he offered. This is an efficient way of highlighting the current relevancy of the bruise for the suspect and for the future viewers of the videotape; that one account for the bruise (police brutality) would have a special status for the legitimacy of the videotape and that that account was refuted.

One use of incorporating a Candidate Answer in a question is to have the recipient provide just the information that is relevant to the immediate concern. There is another use of this strategy that is exhibited in this illustration. In court, the adversarial parties make claims and counterclaims to argue their cases. How the testimony is stated matters for the strength of the claim. By incorporating a Candidate Answer in his question, the ADA provided the terms for the suspect's testimony. In specifying "in any way" in the Candidate Answer, the ADA provided for the suspect's negative answer to be a strong, absolute claim, "The bruise is in no way related to the police."

\section{Illustration 8}

[Med.6]

(The high school attendance clerk called to speak with the mother but the absent student answered. When the clerk was told that the mother was not home, she sought some information regarding the absence from the student.)

Clerk: Well how- have you been home from school i:ll Renee,

Stud: Yeah

Clerk: Okay, when was the first day that you were out ill

Stud: I don'know

Clerk: Well you know how long it's been, couple weeks? or what.

Stud: Yeh

In attempting to get information regarding the absence, the clerk asked, "When was the first day that you were out ill"? In this question, the clerk, through an unmarked form, implied that the student should have known the answer. In response, the student claimed that she was not able to give that information ("I don'know").

In her follow-up question, "Well you know how long it's been, couple weeks? or what.", the clerk did not take for granted and/or imply that the student should have known the answer; she included the marker, "[do] you know." At the same time, she incorporated a Candidate Answer, "couple weeks? or what." The Candidate Answer served as a model of a satisfactory answer.

Given the difficulty that the student exhibited or claimed in answering the prior question, the clerk eased up in both her implied expectations of the student's knowledge and in the specificity of the knowledge sought. The clerk provided an approximate or imprecise Candidate Answer, "couple weeks? or what." By providing the Candidate Answer, she cued the student that, unlike the previous question, she now sought only an approximation. When recipients exhibit difficulty in supplying the information that interactants seek, interactants frequently give 'cues' or 'hints' or 'prods' by offering Candidate Answers. 
When a participant incorporates a Candidate Answer in a question, he/she is seen to endorse that Candidate Answer as a likely possibility or as his/her best guess. By saying, "Are you a speech major," a speaker will be seen to be suggesting "speech" as a likely or probable major.

A speaker may know a possible answer to his/her own query but, for any number of reasons, not want to author it. In such circumstances, interactants have options. One obvious option is to solicit the information without including a Candidate Answer (See Illustration 10). Another option is for a speaker to report a possible answer but credit the authorship of it to someone else.

There are two kinds of attributions that may bear on whether speakers incorporate ${ }_{\sigma}$ Candidate Answers in their queries. The first kind includes attributions about the ispeaker's knowledge of the matter at hand; the second kind are attributions of the speaker's attitudes and sympathies toward the relevant actors. Implied knowledge of the speaker. In putting forth a Candidate Answer, a speaker
o recognizably offers the Candidate Answer as a likely possibility. The particular $\dot{\Xi}$ choice of Candidate Answer is treated as a display of the speaker's knowledge of, and Efamiliarity with, the situation. In offering a Candidate Answer, a speaker may be Fpresumed to have drawn on his/her knowledge of, and familiarity with, the situation.

In the following illustration, a student from a fieldwork methods course was sitting win on court hearings.

\section{Illustration 9}

\section{[AM:fieldnotes]}

After all the cases but one had been heard, [the Judge] called out to no one in particular, "Who are these three people," hand sweeping across the front of the room indicating he meant us, a white couple and

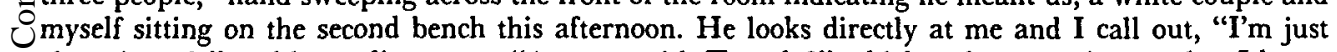
Jobserving, sir" and he replies to me, "Are you with Temple?" which rather surprises me but I know of that there have been law students here observing in the past. ...

¿When the student heard the judge's question, "Are you with Temple?", she reported that her initial reaction was surprise or puzzlement. The surprise or puzzlement Finvolved the issue of how the judge could have known or guessed that she was from "T Temple University. The judge's offering the Candidate Answer, "You are with 을 Temple," was seen as a display of knowledge of, or familiarity with, the student and that was puzzling because she had never met the judge, she was not wearing any OTemple identification, and Temple is not the only university in the area. The puzzle was resolved when she recalled an event (Temple law students previously observed the court) that could have provided the judge the knowledge and experience that was the basis of his Candidate Answer.

In our culture, interactants often are motivated to display what they know, unless there is a reason not to. Across many different circumstances, being knowledgeable is treated as worthy and being unknowledgeable is treated as being unworthy.

In circumstances in which information seekers are motivated to display their knowledge, they may do so by offering Candidate Answers. In offering a Candidate Answer, a speaker produces a display of some degree of knowledge or ignorance, depending on whether the Candidate Answer is right or wrong, plausible or implausible. By offering a Candidate Answer while asking for information, a 
participant may implicitly propose to be, or display being, somewhat knowledgeable even while seeking information (Pomerantz, 1986).

In offering a Candidate Answer a speaker can shape the "context" of the inquiry. If a speaker turns to another for information with a possible answer to the query, he or she may be seen to be "checking it out." If, on the other hand, a speaker seeks information without offering a Candidate Answer, the inquirer more likely may be seen to be without a guess, having no idea about the matter at hand.

Although there are many occasions in which interactants want to claim knowledge and hence offer Candidate Answers, there are other situations in which interactants choose not to offer Candidate Answers. An interactant who wants to elicit independently produced information would not offer a Candidate Answer. An interactant who may want to mobilize a co-interactant to give information, collaborate, or help may do so by presenting him/herself as having no idea about the matter at hand. Someone wanting to be held to lower standards and expectations may present $\mathrm{him} / \mathrm{herself}$ as unknowledgeable.

Implied Attitude and Sympathies of the Speaker. In the cases that I examined, I was impressed by the frequency with which participants incorporated legitimate actions as their Candidate Answers. When interactants asked about their cointeractants' actions, they offered legitimate actions as their Candidate Answers. While there are circumstances in which interactants offer illegitimate actions as their Candidate Answers, I have not collected them and thus will concentrate on participants' offering legitimate actions as their Candidate Answers.

When a speaker proposes a legitimate action as a Candidate Answer, the choice both reflects and proposes a cooperative or friendly relationship. A Candidate Answer is put forth as the speaker's guess and a good likelihood. It can be seen as reflecting the speaker's expectation of the other's behavior. When a speaker offers a Candidate Answer, the Candidate Answer may be read as revealing the speaker's expectations regarding the relevant actors.

In all of the instances presented in this paper in which interactants ask about their co-interactant's actions, the interactants offer legitimate actions as their Candidate Answers. I will re-examine two of the illustrations already discussed to show how speakers reflect and propose friendly or cooperative relationships when they offer legitimate actions as their Candidate Answers.

\section{Illustration 2 (re-examined)}

[Fieldnotes]

I'm getting impatient but wonder if the driver might be waiting to take an incapacitated person to church. I debate about whether to back up and take another street. Then I realize I could ask the driver for information.

I get out of my car and approach his van on the driver's side. He sees me, obviously waiting to speak to him, and rolls down his window.

I ask, "Are you gonna be here awhile?"

The first hint of my constructing a legitimate account for the van driver's actions is contained in my reported thought, "I'm getting impatient but wonder if the driver might be waiting to take an incapacitated person to church." Of the many reasons that drivers may stop in the middle of a road, I conjured up a legitimate reason on his behalf.

When I approached him, my query was, "Are you gonna be here awhile?" A close look at the formulation of the Candidate Answer suggests that it was put forth as a legitimate possibility. The formulation for the amount of time he might be there, 
"awhile," does not name an inappropriately long amount of time. Contrast it, for example, with a formulation in "Are you going to be here all day?" Had I said that, he might well have heard the query not as a request for information but as a complaint or accusation. In offering a Legitimate Action as my Candidate Answer, I was responding to the possibility that he was stopped there legitimately and I helped shape the encounter as non-hostile and the interaction as non-confrontative.

\section{Illustration 5 (re-examined)}

[TC]

(Sue and Gail are friends and neighbors. Sue telephoned Gail just after Gail arrived home.)

Gail: Dju j'see me pull up?

As a Candidate Answer, Gail offered an explanation for how Sue telephoned her $\checkmark$ so soon after she arrived home: that Sue saw her pull up. Her explanation can be seen to be an instance of a legitimate action. The formulation, "saw," names an action for $\vec{\Xi}$ an actor with unspecified intentions. Neighbors, in carrying out their own activities, $\checkmark$ may be expected to "see" their neighbors come and go on some occasions. This is in $\infty$ contrast to formulations for actors with possibly illegitimate intentions, such as, $\stackrel{+}{+}$ "Were you spying on me?" or "Have you been watching me?" These latter formulations might well be heard as accusations. As Candidate Answers can be read as revealing the speakers' expectations, such accusations might both reflect and further shape the relationship as non-cooperative.

On many occasions of seeking information, interactants proffer legitimate actions 0 as Candidate Answers. In so doing, they help promote a friendly or cooperative atmosphere. On other occasions interactants find themselves not wanting to, or being . able to, offer legitimate actions as Candidate Answers. One type of circumstance in J which an interactant may decline to offer a Legitimate Action as a Candidate Answer is when he/she thinks it likely that a co-participant has performed an improper or Eproblematic action.

We generally do not have access to what interactants think and then withhold. Illustration 10 is reported to be one such occasion in which a Candidate Answer was Ifthought of and then withheld. It illustrates what an interactant may do when an illegitimate action is a good likelihood.

\section{Illustration 10}

Ann's aunt, Molly, tried to telephone Ann on the Jewish holiday, Yom Kippur. Unlike some of the extended family who are quite religious, both Ann's and Molly's families are not. The next day, Molly reached Ann at home. Early in their phone conversation, Molly reported having tried Ann the day before. In response, Ann did not offer the information apparently sought, namely, where she was on $\bigcirc$ Yom Kippur. Molly then asked Ann where she was the day before. Ann reported that she was working in her office. At that point, Molly told Ann that when no one answered, they thought she may have gone to services if her relatives had sufficiently pressured her to.

Upon getting no answer at Ann's house the day before, Molly and her family came up with the likely possibility that Ann went to services. Although they voiced this likely possibility among themselves the day before, Molly did not offer it as a Candidate Answer to Ann, for example, "Did you go to services yesterday?". It seems that Molly knew that 'going to services' was not a normal or legitimate action for Ann. Rather than proffering an unusual or problematic action as a Candidate Answer, Molly first sought information by giving information (Pomerantz, 1980) and then asked for an account with no Candidate Answer offered. When Molly subsequently named the action that reportedly had been their best guess (that is, 
"went to services"), she provided an account ("relatives' pressure") for how Ann might have performed it.

Although Molly and her family guessed or suspected that Ann went to services, Molly sought the information without using the guess. This suggests that when speakers seek information, the type of guess they make bears on the strategy they select to seek the information. When a speaker thinks that a co-participant may have performed an inappropriate, unusual, or illegitimate action, that speaker may hesitate to name either a legitimate action or an illegitimate action as a Candidate Answer. This would not be surprising since (a) a Candidate Answer is treated as a display of the speaker's knowledge, and (b) naming an Illegitimate Action is recognizable as an accusation or complaint.

\section{DISCUSSION}

This paper analyzed some features of offering a Candidate Answer. After briefly summarizing the analytic proposals, I offer some implications that this research has for other research in the field.

The following points summarize features of the information seeking strategy of offering a Candidate Answer.

1. Participants who seek information are presumed to have a purpose for seeking the particular information. In determining just what information to offer, a respondent considers the information-seeker's explicitly stated or inferred purposefor-asking.

2. In offering a Candidate Answer, a speaker provides a model that can guide the respondent to know what would satisfy the purpose-for-asking. This is useful when a speaker wants a recipient to respond with particular information, respond in a particular way, and/or respond "efficiently." It is also useful when a recipient is expected to have difficulty in providing the sought-after information. Incorporating model answers may be used to help or cue recipients as well as to direct or constrain them.

3. By incorporating a Candidate Answer, a speaker can display his/her knowledge of, and familiarity with, the situation.

4. By incorporating a Candidate Answer, a speaker can display his/her attitude toward, or expectations of, the relevant persons. In offering a Legitimate Action as a Candidate Answer, a speaker may be helping to shape the relationship as friendly and/or cooperative.

5. A speaker may offer a Candidate Answer if he/she can come up with a likely possibility and there is no reason to withhold the likely possibility. Some reasons why participants who have come up with Candidate Answers choose strategies other than offering the Candidate Answers are to gain information that might otherwise be unavailable, to hear another's answer expressed independently, or to avoid accusing a co-participant.

Berger and Bradac (1982) describe two types of interactive strategies: interrogation and self disclosure. About interrogation they write: "One of the most obvious ways of gaining information about a stranger is simply to ask the stranger questions about himself or herself." The examples they offer are, "Where are you from?", "What is your main subject?" and "Where do you live?". Using the distinctions presented in this paper, these are examples of not offering Candidate Answers. According to Berger and Bradac, one of the purposes of information seeking during an initial interaction between strangers is to reveal common ground between the 
interactants. As common ground is established, the participants change the kinds of questions that they ask. Since interactants offer Candidate Answers when they want to show a degree of familiarity with the subject or topic, I would expect Candidate Answers to be offered by interactants in establishing common ground and building interpersonal relationships.

The exchange of information is a vital part of decision making in small groups. Two of the categories in Bales' scheme for Interaction Process Analysis are "asks for information" and "gives information" (Bales, 1969). These two are conceptualized as reciprocal, or opposite, pairs. The research presented in this paper questions the appropriateness of conceptualizing asking for information and giving information as dichotomous I would argue that seeking information and giving information are actions that lie along a continuum. An essential feature of asking a question is that $\rightarrow$ the speaker makes an implicit claim regarding how knowledgeable he or she is. A ispeaker may ask from the position of not making any claims of knowing the answer, తusing an open question (for example, "Where is Temple University?" to making

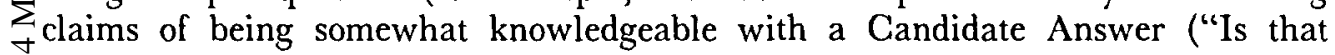
-Temple?") or a tag ("That's Temple, isn't it ?").

This paper analyzed a method or strategy that participants use in seeking $\underset{J}{ \pm}$ information. My assumption was that members of our culture have a repertoire of methods to accomplish their actions and that they select a method according to their . analysis of the situation. In tracking how different strategies were used on different . ow their analyses bear on strategy selection.

\section{NOTES}

'Margaret McLaughlin offered the concept of "model" for my analysıs of this technique of information seekıng

\section{REFERENCES}

Bales, R R (1969) Personality and interpersonal behavior New York Holt, Rinehart, and Winston

Berger, C R, \& Bradac, J J (1982) Language and soctal knowledge Uncertainty in interpersonal relations London Edward Arnold

ZGarfinkel, H (1967) Studies tn ethnomethodology Englewood Clıffs, NJ Prentice Hall

Heritage, J , \& Atkinson, J M (1984) Introduction In J M Atkinson \& J C Heritage (Eds), Structures of social action Studies in conversation analysis (pp 1-15) Cambridge Cambridge University Press

Jackson, S (1986) Building a case for claims about discourse structure In D G Ellıs \& W A Donohue (Eds), Contemporary issues in language and discourse processes (pp 129-147) Hillsdale, NJ Lawrence Erlbaum

Jefferson, G (1985) An exercise in the transcription and analysis of laughter In T A van Dijk (Ed), Handbook of discourse analysis, Vol 3 Discourse and dialogue (pp 25-34) New York Academic Press

Katz, J (1983) A theory of qualitative methodology The social system of analytic fieldwork In $R$ M Emerson (Ed), Contemporary field research (pp 127-148) Prospect Heights, IL Waveland Press

Pomerantz, A (1980) Telling my side 'Limited access' as a 'fishing' device Soctological Inquiry, 50, 186-198

Pomerantz, A (1986, November) Features of novice-expert communication Paper presented at the annual meeting of the Speech Communication Association, Chicago, IL

Pomerantz, A, \& Atkınson, JM (1984) Ethnomethodology, conversation analysis and the study of courtroom interaction In D J Muller, D E Blackman, \& A J Chapman (Eds), Topics in psychology and law (pp 283-297) Ghichester Wiley

Sacks, H (1964) [Untitled] Unpublished lecture, Fall 1964, Tape 5(2), pp 1-6

Sacks, H (1966) [Untitled] Unpublished lecture, Spring 1966, Lecture 15, pp 8-9

Sacks, H (1966) [Untitled] Unpublished lecture, Fall 1966, Lecture 10, pp 15-16

Sacks, H (1967) [Untıtled] Unpublıshed lecture, Fall 1967, Lecture 14, p 11

Sacks, H , Schegloff, E A , \& Jefferson, G (1974) A simplest systematics for the organızation of turn-takıng for conversation Language, 50, 696-735 